\title{
The method of magnetic coercimetry and its application to assess the residual life of lifting equipment
}

\author{
Boris Popov ${ }^{1}$, Sergei Evdokimov ${ }^{2}$, Olga Leonova ${ }^{3, *}$ and Yury Sokolov ${ }^{4}$ \\ ${ }^{1}$ Engineering and Design Centre "Crane" LLC, Moscow, Volgograd prospect, 47, Russia \\ ${ }^{2}$ Mechel-Trans" operator company LLC, Moscow, Krasnoarmeyskaya street, 1, Russia \\ ${ }^{3}$ Moscow State Academy of Water Transport, Moscow, Novodanilovskaya embankment, 2/1, Russia \\ ${ }^{4}$ Company Quanty Pty. Ltd., PO Box 255, Kippa-Ring, QLD, 4021, Australia
}

\begin{abstract}
Material fatigue damage accumulation is recognized as one of the least inspectable and controllable operational damage mechanisms of crane structures. The scope method measures electro-magnetic properties of steels being in service, to assess their relative changes induced by the fatigue damage accompanying microstructural effects. The authors' theoretical and experimental research suggested that the most relevant magnetic parameter to measure is the coercive force $\mathrm{Hc}$, which is a characteristic of ferritic steels' magnetization-demagnetization hysteresis loop. The authors proposed and developed a correction factor to normalize changes in $H_{c}$ for various carbon steel thicknesses in the practical range from $5 \mathrm{~mm}$ to $20 \mathrm{~mm}$, and drawn the coercive force nomograms which quantify the extent of damage for typical structural steels used in cranes. This research provided a scientifically justified basis for structures remnant resource assessments. Application of the Coercimetric method contributes into the risk control and promotes industrial safety in lifting equipment operations. The method itself can be practically useful for resolving integrity management challenges in a wide range of industries.
\end{abstract}

\section{Introduction: the coercive force and microstructural changes in steels}

Ferromagnetic effects are explained by microscopic magnetic domains' orientation changes. An applied and increasing magnetic field re-orients these domains away from their virtual 'equilibrium' positions up to a saturation point, where the orientation is maximally favorable for a maximum magnetic flux density, and no further magnetization occurs. The removal of the external field permits the domains to return into their equilibrium positions, however, a residual magnetic flux remains as it is evident from the magnetization hysteresis loop (Fig. 1, a). The microscopic domains orientation is obviously dependent on the material imperfections and plasticity, as the orientation is forced to change mechanically in a process of damage accumulation.

\footnotetext{
* Corresponding author: pptmir@mail.ru
} 
The Coercimetric method's fundamental magnetic parameter $H_{c}$ (the coercive force, dimension $\mathrm{A} / \mathrm{cm}$ ) has a high sensitivity to changes of steel structure properties, which result from the material cyclic deformation in operation. The coercive force $H_{c}$ is the amount of an external magnetic field, which is required to reduce the material residual magnetic flux (or magnetization) to zero (Fig. 1,a).

The coercive force is a function of the metal grain size, dislocations density, texture features, micro plastic deformation, residual stresses and domain structure. According to the theoretical and practical research in magnetic measurements [1-6], the following relations apply.

The coercive force decreases with the grain size increase:

$$
H_{c}=K \cdot \frac{\gamma}{\mu_{0} \cdot M_{s}} \cdot \frac{1}{d_{3}}
$$

where $K$ - magnetic anisotropy constant; $\gamma$ - material density $\left[\mathrm{kg} / \mathrm{m}^{3}\right] ; \mu_{\mathrm{o}}-$ magnetic permeability of vacuum $[\mathrm{H} / \mathrm{m}] ; M_{s}$ - saturation magnetization $[\mathrm{T}] ; d_{3}-$ metal grain size $[\mathrm{m}]$.

The coercive force increases along with the dislocations density. Crystalline domain boundaries are pinned by dislocations. They bend and then displace stepwise when a critical magnetic field HKP is achieved, meaning that the domain boundaries tear off from the defects. The following function between the coercive force $H_{c}$ and the dislocations density $\rho$ was found experimentally:

$$
H_{c}=C \cdot \sqrt{\rho}
$$

where $C$ - material constant.

The coercive force is proportional to the volumetric fraction of inclusions in the metal:

$$
H_{c}=P_{0} \cdot \frac{K_{э \phi}}{\mu_{0} \cdot M_{s}} \cdot Y^{m}
$$

where $Y$ - relative volumetric concentration of inclusions; $P_{0}$ - inclusions dispersion factor; $K_{\text {эф }}$ - effective constant of magnetic anisotropy; $\mu_{\mathrm{o}}$ - magnetic permeability of vacuum $[\mathrm{H} / \mathrm{m}] ; M_{s}$ - saturation magnetization $[\mathrm{T}] ; m$ - either $1 / 2,2 / 3$ or 1 depending on the material type.

The coercive force is directly proportional to the internal (and also residual) stresses:

$$
H_{c}=\frac{\delta \cdot \lambda_{s}}{\mu_{0} M_{s}} \cdot \frac{\Delta \sigma_{i n}}{\Delta x}
$$

where $\delta$ - domain boundary width $[\mathrm{m}] ; \lambda_{s}$ - magnetostriction; $\Delta \sigma_{\text {in }}$ - average amplitude of internal stress; $\Delta x$ - domain boundary thickness $[\mathrm{m}] ; \mu_{\mathrm{o}}$ - magnetic permeability of vacuum $[\mathrm{H} / \mathrm{m}] ; M_{s}-$ saturation magnetization $[\mathrm{T}]$.

The material intrinsic coercive force increases along with its plastic deformation:

$$
H_{c}=H_{c o} \cdot \kappa \cdot \varepsilon^{\frac{1}{2}}
$$

where: $H_{\mathrm{co}}$ - the material intrinsic (juvenile) coercive force $[\mathrm{A} / \mathrm{cm}] ; k-$ alloy constant; $\varepsilon-$ plastic deformation accumulated.

The coercive force is a function of crystalline and domain structure:

$$
H_{c}=H_{c}^{\min }+\alpha \cdot(1-\cos (\theta))
$$

where: $H_{\mathrm{c}}{ }^{\mathrm{min}}$ - vector quantity matching the easy axis of magnetization; $\alpha$-constant; $\theta$-curie temperature. 


\section{Coercive force correlation with plastic strains}

The above equations indicate the complexity of the coercive force evolution in a nonstationary cyclic loading environment, which is applicable to cranes and other real structures. Nevertheless, in a stationary cyclic deformation test, an increase of load or deformation is accompanied by an increase of $H_{c}$, which follows nearly the same path as the loading parameter. The coercive force follows the stress-strain curve, with the distinct branches of elastic and elasto-plastic deformation present, and followed by the stages of softening and transition to failure as well.

The coercive force increases during a structure operational life, and can rise to between $100 \%$ and $400 \%$ of the initial value $H_{c o}$, depending on a particular steel composition and grade. It is also notable that a steel member which was ever loaded beyond its yield stress, will never show the initial value $H_{c o}$ again (at that local area of yielding), but will possess a new, elevated coercive force value $H_{c f}$, according to [7].

The physical relationship between the $H_{c}$ and the damage accumulation in a fatigue cycle is analogous to the mechanical hysteresis of softening low alloy steels in cyclic loading, as shown in Fig. 1. All major magnetic parameters linked to the changes of metal structure and its stress-strain condition can be expressed from a coercive force value.
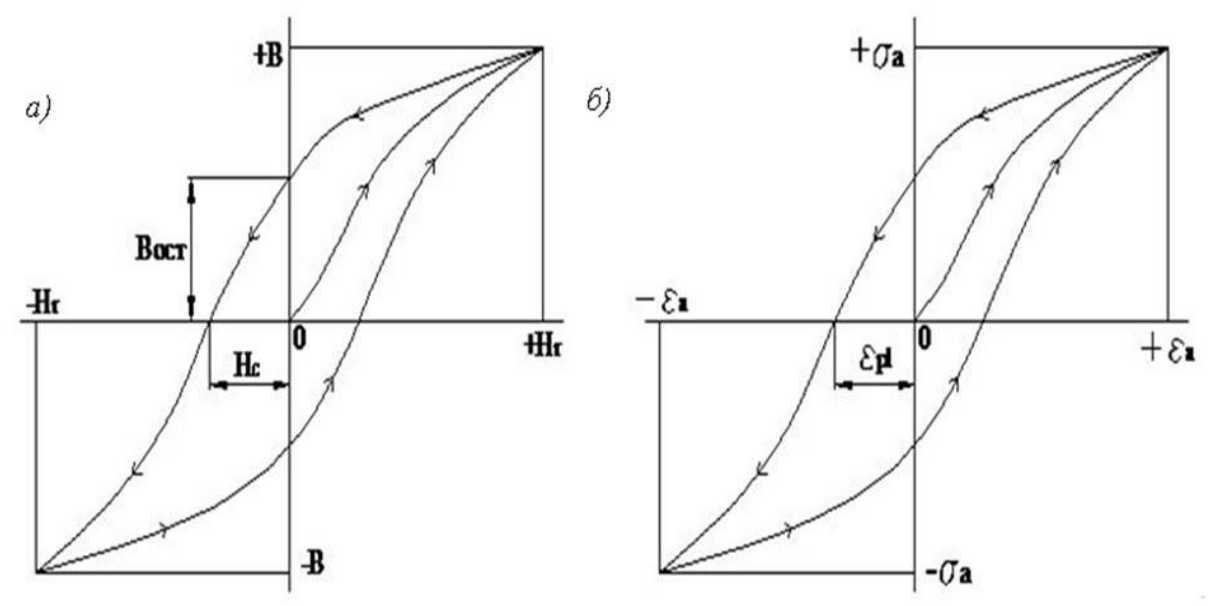

Fig. 1. Magnetic hysteresis loop and deformation hysteresis loop

In testing, the coercive force $H_{c}$ and the plastic deformation $\varepsilon_{p l}$ change in a load cycle simultaneously. Both respond to the load by means of basic mechanical interactions in the crystalline structure [9]. Therefore, for practical purposes these resemble parameters can be approximated by the Ramberg-Osgood equation:

$$
\varepsilon_{p l}=\frac{\sigma}{E}+\left(\frac{\sigma}{K}\right)^{\frac{1}{n}} \quad \text { and } \quad H_{c}=\frac{B}{E}+\left(\frac{B}{K}\right)^{\frac{1}{n}}
$$

where: $\sigma$-stress amplitude [MPa]; $E$ - elasticity modulus [MPa]; $K$ - material cyclic stress constant; $n$-strain hardening exponent; $B$ - residual magnetic flux density [T].

In this way, the changes in coercive force accumulated over a structure life do characterize the material microstructural changes (equations 1 to 6 ), and besides, these changes are directly proportional to the amount of plastic deformation the material experienced (equation 7). 


\section{Experimental values of the coercive force in structural steels}

Standard tensile tests were performed to evaluate reference changes of the material intrinsic coercive force $\left(H_{c o}\right)$, which would be equivalent to the yield stress $\left(H_{c m}\right)$ and ultimate tensile stress $\left(H_{c b}\right)$ occurrence. The standard specimens of four carbon steel typically used in crane structures were of $6 \mathrm{~mm}$ to $8 \mathrm{~mm}$ thickness. The coercive force was being measured simultaneously with the specimens tensioning, using the coercimeter KRM-Ch-K2M made by the "NPF CNR" company and equipped by an attachment Hall sensor [8]. The test results are presented in Table 1 [10].

Table 1. Mechanical and magnetic properties of crane steels

\begin{tabular}{|c|c|c|c|c|c|c|c|}
\hline \multirow{2}{*}{ Steel } & \multirow{2}{*}{$\begin{array}{l}\text { European } \\
\text { close } \\
\text { analogue } \\
\text { Material } N_{o}\end{array}$} & \multicolumn{2}{|c|}{ Stress [MPa] } & \multirow{2}{*}{$\begin{array}{c}\begin{array}{c}\text { Elongation at } \\
\text { break [\%] }\end{array} \\
\delta\end{array}$} & \multicolumn{3}{|c|}{ Coercive force $[\mathrm{A} / \mathrm{cm}]$} \\
\hline & & $\begin{array}{c}\text { yield } \\
\sigma_{\mathrm{T}} \\
\end{array}$ & $\begin{array}{c}\text { ultimate } \\
\sigma_{\mathrm{B}}\end{array}$ & & $\begin{array}{c}\text { initial } \\
H_{c o}\end{array}$ & $\begin{array}{l}\text { yield } \\
H_{c m}\end{array}$ & $\begin{array}{c}\text { ultimate } \\
H_{c B}\end{array}$ \\
\hline ВСтЗсп & 1.0038 & 245 & 420 & 26 & 2,8 & 5,5 & 7,0 \\
\hline St38b-2 & 1.5515 & 240 & 430 & 25 & 2,0 & 5,2 & 6,2 \\
\hline 09Г2C-12 & $1.5111^{*}$ & 350 & 500 & 21 & 3,5 & 7,5 & 9,5 \\
\hline 10ХСНД & $1.5701 *$ & 400 & 540 & 19 & 4,5 & 10,5 & 13,5 \\
\hline
\end{tabular}

* these analogues are very approximate and provide a certain match by a steel composition only

The test results treatment revealed a correlation between the coercive force $H_{c}$ and the residual elongation $\varepsilon$ [\%] of the specimens, as shown in Fig. 2 [8].

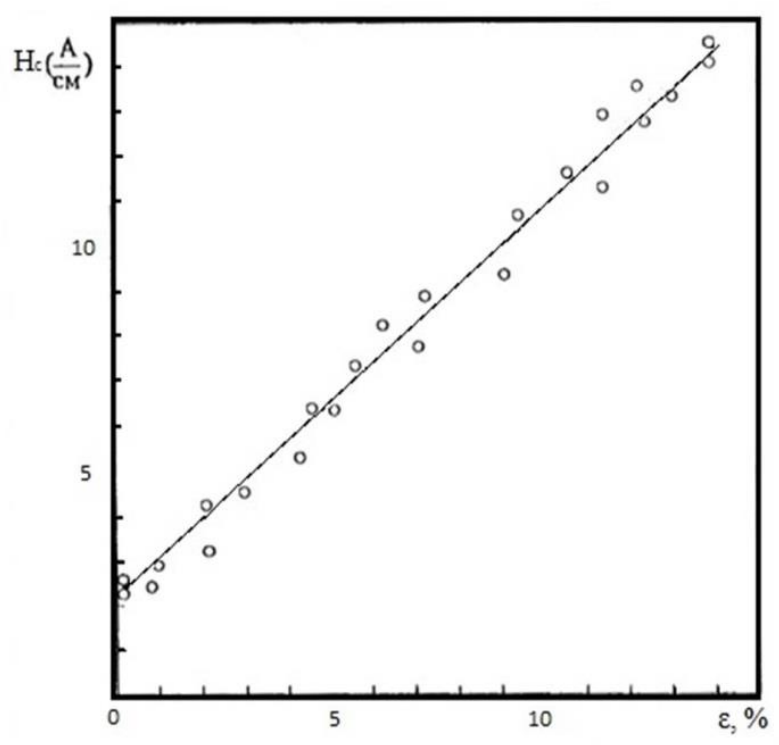

Fig. 2. Coercive force versus residual elongation in static tension beyond yield strength ( $5 \mathrm{~mm}$ to $8 \mathrm{~mm}$ thick specimens made of steels Ст3, ВСт3сп and Ст 20).

Statistical treatment of fatigue test data with monitored $H_{c}$ provided the nomograms (Fig. 3), which plot the remnant resource Rres [\%] versus the equivalent coercive force measured. 


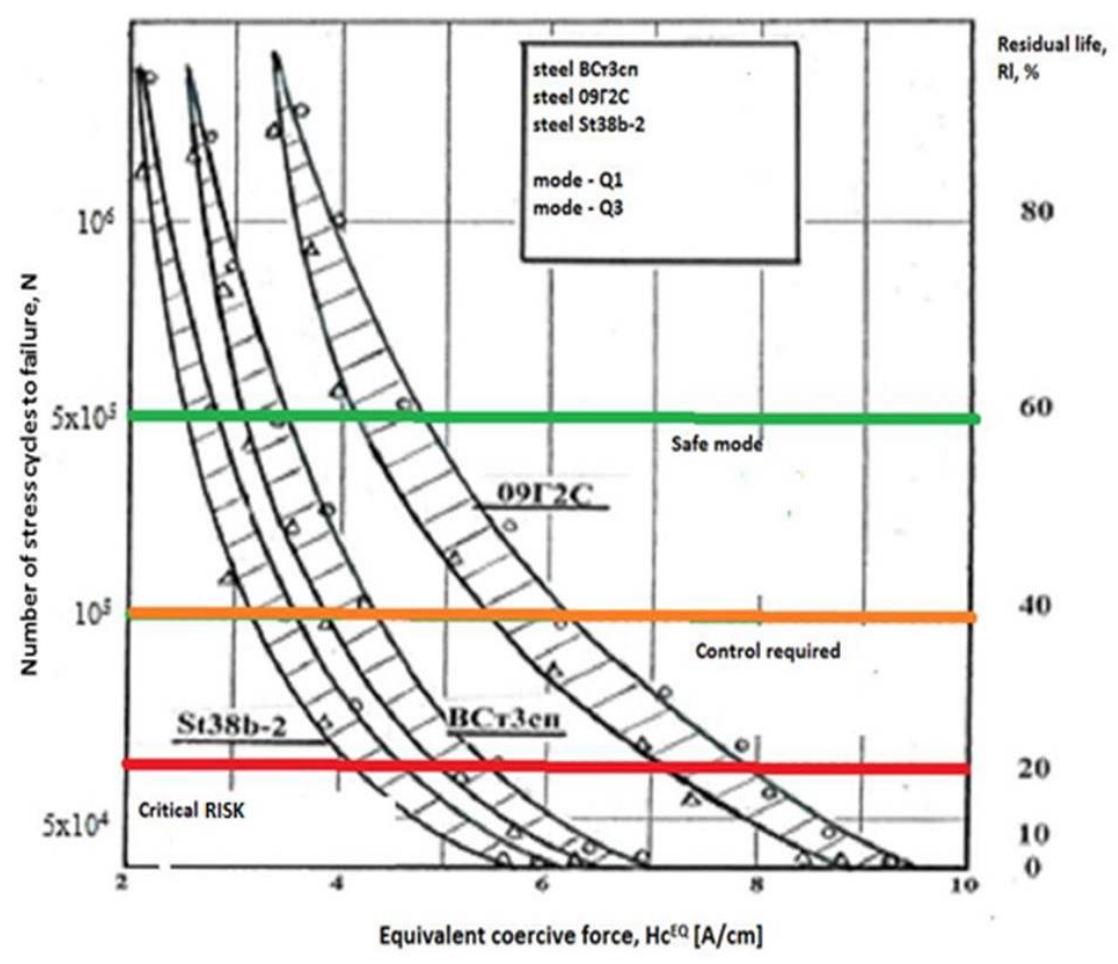

Fig. 3. A nomogram for remnant resource calculation, based on $7 \mathrm{~mm}$ thick specimens data.

The coercive force increase in each of the tested steels has shown a spread depending on the testing regime. The lower bound values correspond to a soft regime, the upper bound values - to a sharp loading regime.

The nomogram shows the example qualitative boundaries of a steel structure damage extent:

- critical risk operation - repair required, the remnant resource is less than $20 \%$ (e.g. cyclic microstructural changes in excess of an equivalent static yield stress loading);

- risk control or monitoring requirement, the remnant resource is between $20 \%$ and $40 \%$;

- safe operation, the remnant resource is greater than $40 \%$.

In this way, in-situ collected coercimetry data and the nomograms (Fig. 3) constructed from this data provide a robust method for fatigue damage accumulation evaluation and for risk based decision making regarding structural life extension perspectives. At least, relative risks amongst equipment units can be assessed directly from the measurements, with a further potential for a numeric evaluation of the remnant resource. The latter option would also require regular re-evaluation or constructing damage models in terms of the structure operating parameters.

\section{Material thickness factor}

Fig. 3 was plotted using the $7 \mathrm{~mm}$ thick specimens data. It was found that, at varying thickness, same extent of the steel microstructural damage is measured as different values of the coercive force $[1,11]$. This can be explained by a different amount of the rolling 
deformation induced by the steelmaking process. The authors proposed a thickness factor $k_{T}$ to normalize the $H_{c}$ measurements of $5 \mathrm{~mm}$ to $20 \mathrm{~mm}$ steel sheets to the testing $(7 \mathrm{~mm}$ ) data:

$$
H_{c} E Q=H_{c} / k_{T}
$$

To determine the thickness factor $\mathrm{kT}$, the steels $\mathrm{CT}-3 \mathrm{c} п, 09 Г 2 \mathrm{C}, \mathrm{St} 38 \mathrm{~B}-2$ were tested, with the results tabulated in tabl.2.

Table 2. Material thickness factor $\mathrm{kT}$ for equivalent coercive force $H_{C} E Q$ calculation

\begin{tabular}{|c|c|c|c|c|c|c|c|c|c|c|c|c|c|}
\hline \multirow{3}{*}{ Steel } & \multicolumn{10}{|c|}{ Sheet thickness $\mathrm{t}[\mathrm{mm}]$} \\
\cline { 2 - 14 } & 2 & 4 & 5 & 6 & 8 & 10 & 12 & 14 & 15 & 20 & 25 \\
\cline { 2 - 13 } & \multicolumn{10}{|c|}{ Thickness factor $k_{T}$} \\
\hline Ст3сп & 1,6 & 1,25 & 1,2 & 1,05 & 0,95 & 0,9 & 0,8 & 0,78 & 0,75 & 0,62 & 0,6 \\
\hline 09Г2C & 1,6 & 1,3 & 1,15 & 1,0 & 0,9 & 0,85 & 0,8 & 0,75 & 0,71 & 0,6 & 0,55 \\
\hline St38 b-2 & - & 1,1 & 1,0 & 0,96 & 0,82 & 0,75 & - & 0,69 & 0,58 & 0,53 & \\
\hline
\end{tabular}

The obtained thickness factors correlate well (Fig. 4) across the tested low carbon and low alloy steels. This proves the higher sensitivity of the coercive force to the material thickness.

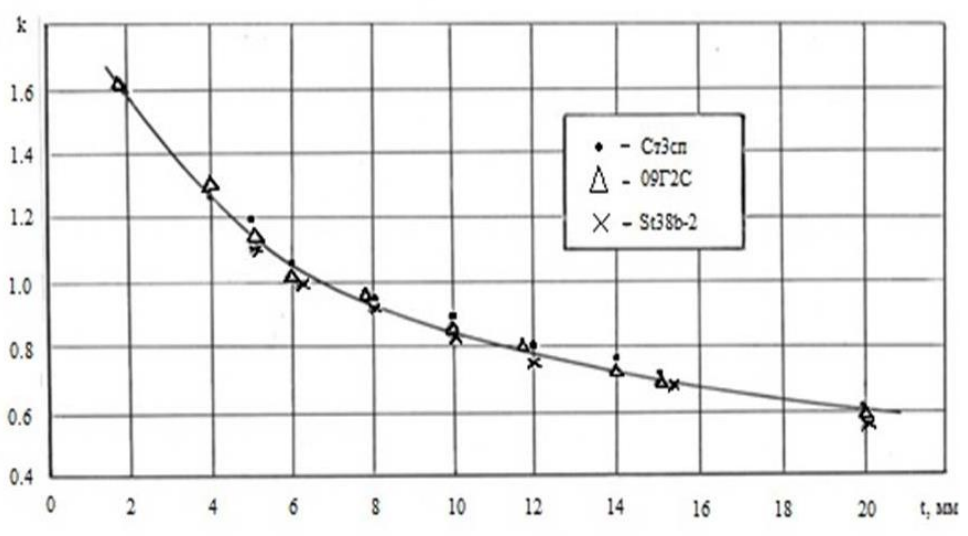

Fig. 4. Thickness correction factor correlation.

\section{Case Study: Coercimetry application for port cranes integrity condition assessment}

The above methodology of structural remnant resource evaluation was applied to aged port cranes Albatross 10/32. The column support plate of seven cranes was subjected to coercimetry examination, as tabulated in Table 3.

The crane number 5, although operated less than others, has shown the coercive force values far greater than the rest of the sample (bold numbers in Table 3). This was attributed to its usage for personnel training. Unexperienced crane operators usually subject the structures to impacts, and the elevated coercive force readings proved a significant microstructural damage at the tested locations. As a follow up measure, the crane number 5 was transferred to a milder operation regime with a regular integrity re-evaluation requirement. Namely, portal cranes can be used for various elements of a cargo transhipment process. Some of these elements involve more mechanical work per cycle, 
and some - less. This provides an additional degree of freedom by matching cranes' actual integrity condition with available loading options.

Table 3. Crane column support plate coercive force $H c[\mathrm{~A} / \mathrm{cm}]$ measurement points and results

\begin{tabular}{|c|c|c|c|c|c|c|}
\hline \multirow{4}{*}{$\begin{array}{c}\text { Crane } \\
\text { number, } \\
\text { year built }\end{array}$} & \multirow{4}{*}{$\begin{array}{c}\text { Total } \\
\text { operational } \\
\text { time [hours] }\end{array}$} & \multirow{4}{*}{$\begin{array}{c}\text { Sensor } \\
\text { orientation }\end{array}$} & \multicolumn{4}{|c|}{ Measured sheet thickness $15,7 \mathrm{~mm}$ to $16,5 \mathrm{~mm}$} \\
\hline & & & & & & \\
\hline & & & \multicolumn{4}{|c|}{ Measurement point number } \\
\hline & & & 15 & 16 & 17 & 18 \\
\hline \multirow{2}{*}{ №1 } & \multirow{2}{*}{38500} & $\uparrow$ & 2,0 & 2,4 & 2,5 & 2,3 \\
\hline & & $\rightarrow$ & 2,3 & 2,7 & 2,3 & 2,8 \\
\hline \multirow{2}{*}{ №2 } & \multirow{2}{*}{49100} & $\uparrow$ & 2,0 & 2,6 & 2,5 & 2,7 \\
\hline & & $\rightarrow$ & 2,6 & 2,4 & 2,5 & 2,4 \\
\hline \multirow{2}{*}{ №3 } & \multirow{2}{*}{46200} & $\uparrow$ & 2,9 & 3,8 & 3,1 & 2,7 \\
\hline & & $\rightarrow$ & 3,6 & 3,0 & 3,7 & 3,7 \\
\hline \multirow{2}{*}{ №4 } & \multirow{2}{*}{49300} & $\uparrow$ & 1,7 & 2,7 & 1,9 & 2,9 \\
\hline & & $\rightarrow$ & 2,0 & 2,7 & 3,3 & 2,4 \\
\hline \multirow{2}{*}{ №5 } & \multirow{2}{*}{38200} & $\uparrow$ & 5,4 & 5,5 & 2,6 & 2,4 \\
\hline & & $\rightarrow$ & 6,0 & 5,5 & 2,5 & 2,8 \\
\hline \multirow{2}{*}{ №6 } & \multirow{2}{*}{60300} & $\uparrow$ & 3,0 & 2,3 & 2,6 & 2,5 \\
\hline & & $\rightarrow$ & 3,0 & 2,2 & 3,0 & 3,0 \\
\hline \multirow{2}{*}{ №7 } & \multirow{2}{*}{63900} & $\uparrow$ & 2,9 & 2,9 & 3,0 & 2,4 \\
\hline & & $\rightarrow$ & 2,9 & 2,9 & 3,1 & 3,6 \\
\hline
\end{tabular}

The coercimetric method was also successfully trialed on the port crane model Albrecht 10/32 portal strainer beam, to evaluate an acceptability of its plastic deformation.

This applied research facilitated the development of the Organizational Standard CTO "Port crane steel structure diagnostics - the magnetic coercimetry method" and of the procedure "Crane Albatross 10/20-32/16-10.5 magnetic examination passport". Depending on the coercimetric examination results, some cranes were recommended for a continued operation, as their operational safety didn't deteriorate essentially.

\section{Conclusion}

Contemporary hazardous plant legislations are setting increased requirements to industrial safety examinations. Conventional NDE techniques identify and characterize defects, but don't offer a remnant life resource or risk levels estimates as such. This implies lab our consuming fitness-for-service or other risk assessments to follow-up an inspection data collected. The Coercimetry Non-Destructive Evaluation method discussed here provided a robust alternative to analytical assessments of an actual integrity condition, and clarified the remnant resource perspectives of crane steel structures in cyclic operation. This is because the scope method evaluates microstructural changes of the material accumulated in a volume, and is therefore a structure-scopic method, as opposed to macro-scopic evaluation methods which characterize defects of an above-threshold size. In this way, the coercimetry facilitates a screening of the actual mechanical damage accumulation prior to a detectable size defect was found, even following repairs, thereby serving as a risk level assurance and material quality assurance simultaneously. The coercimetry method can facilitate in-situ fatigue damage screening in various industries, with growing applications in transportation (shown here), in railroad [12], power generation [13], oil and gas [14], and more [15]. 


\section{References}

1. V.A. Popov, V.A. Gudoshnik Art-Press Publishing House 544 (2016)

2. S.V. Vonsovskij M. Science 1032 (1971)

3. M.I. Mikheev, E.S. Gorkunov M.: "Nauka" 252 (1993)

4. V.E. Scherbinin, E.S. Gorkunov Ekaterinburg: Uro Ran 264 (1996)

5. G.V. Bida, E.S. Gorkunov, V.M. Shevnin Ekaterinburg: Uro Ran 252 (2002)

6. N. Sevryugina J. MATEC Web of Conf. RSP. 2600151 (2017)

7. G.Y. Bezludko, B.E. Popov, R.N. Solomakha Coercive force method today. In the world of non-destructive testing, No. 4, 2015. p. 4-8.

8. TWY "TAP" ICC-007-97-02. Magnetic stress-deformed state control and remaining life of lifting constructions in their surveys and technical diagnosis (examination of industrial safety) laboratory. Diagnostics of materials " 6(80) 29-33 (2014)

9. B. Popov, Magnetic control fatigue resistance of welded joints. In the world of nondestructive testing 18(4) 17 - 21 (2015)

10. O.V. Leonva, S.V. Evdokimov, B.E. Popov Mater. XVIII Moscow Inter. Interuniversity scientific-technical Conf.: M. 139 (2015)

11. O.V. Leonva, B.E. Popov, S.V. J. Quality and Life 4(20) 2018

12. G. Bezlyudko, R. Solomakha, A. Lukina Mater.19th World conf. on Non-Destructive Testing (2016)

13. L.S. Ozhigov et al Dir. 1 (101) (2016).

14. S. Mitropolskaya Mater. Conf. WIT Transactions on Ecology and The Environment, WIT Press 186 (2014)

15. Sevryugina N S Advances in Intelligent Systems and Computing 692 273-81 (2018) 